\title{
MATERIAL CAUSE AND SYLLOGISTIC NECESSITY IN POSTERIOR ANALYTICS II 11*
}

\author{
PaOlo Fait \\ https:/ / orcid.org/0000-0002-8579-0667 \\ University of $\mathrm{Oxf}$ ord \\ New College \\ United Kingdom \\ paolo.fait@new.ox.ac.uk
}

\author{
Article info \\ CDD: 185 \\ Received: 28.10.2019; Accepted: 31.10.2019 \\ DOI: http://dx.doi.org/10.1590/0100-6045.2019.V42N4.PF
}

Keywords

Aristotle

Syllogism

Necessity

Material cause

Posterior Analytics

Teleology

Abstract: The paper examines Posterior Analytics II 11, 94a20-36 and makes three points. (1) The confusing formula 'given what

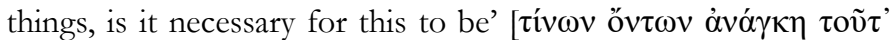
Eivol] at a21-22 introduces material cause, not syllogistic necessity. (2) When biological material necessitation is the only causal factor, Aristotle is reluctant to formalize it in syllogistic terms, and this helps to explain why, in II 11, he turns to geometry in order to illustrate a kind of material cause that can be expressed as the middle term of an explanatory syllogism. (3) If geometrical proof is viewed as a complex construction built on

* I thank Fabio Acerbi, Lucas Angioni, Giulio Di Basilio and Breno Zuppolini for their help and their comments. I am particularly indebted to Diana Quarantotto for invaluable written remarks on a very short notice. 
simpler constructions, it can in effect be described as a case of purely material constitution.

Posterior Analytics II 11 raises such severe exegetical problems that W.D. Ross has ranked it among the most difficult chapters in Aristotle. ${ }^{1}$ Indeed, every paragraph is problematic in its own way, and the opening section on which I shall presently focus, is not less intractable than the rest. First, Aristotle seems to conflate two important notions of his philosophy: the necessity of material $^{2}$ causation and syllogistic or logical necessity. Second, the following paragraph compounds the difficulty by illustrating material causation, not, as the reader might expect, with one of the familiar examples from natural processes, but with an obscurely phrased geometrical example. These two problems will be tackled in order by the two sections of this paper.

\section{SYLlOGISM AND MATERIAL CAUSE}

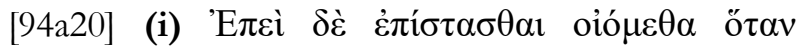

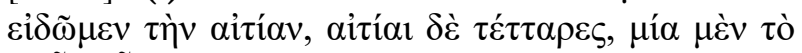

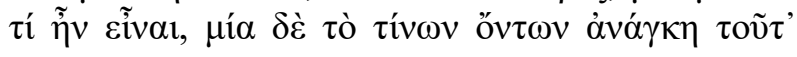

\footnotetext{
1 For commentaries and extensive discussions on Posterior Analytics II 11 see Ross (1949), Barnes (1994), Detel (1993), Leunissen (2010b).

2 Ever since Ross (1949) denied that the second aitia in Posterior Analytics II 11 is matter (see below n. 10), scholars often use scare quotes, or the less committal 'quasi-matter', or the entirely neutral 'grounding' or 'necessitating ground', to signal that what is introduced is not, or not precisely, the familiar Aristotelian concept of matter. We will see that Ross's worries can be defused.
} 


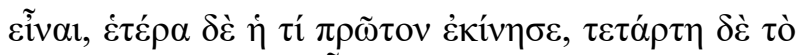

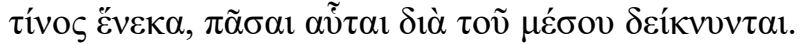

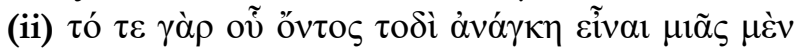

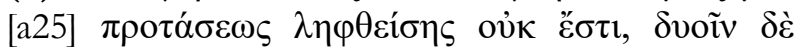

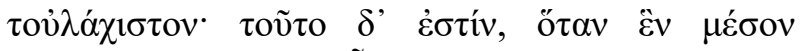

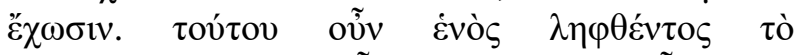

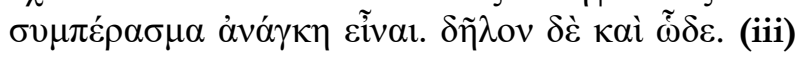

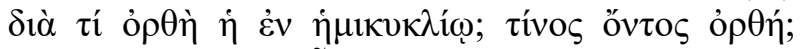

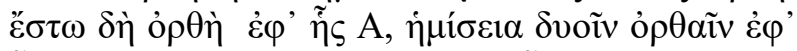

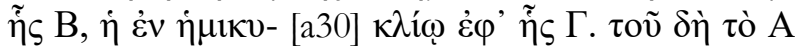

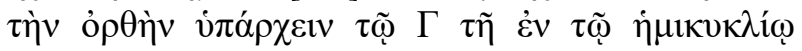

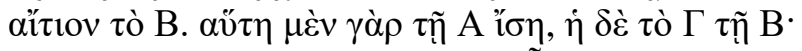

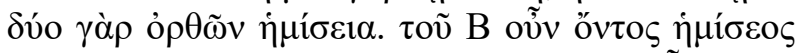

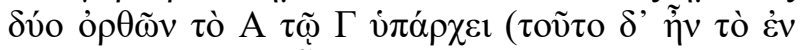

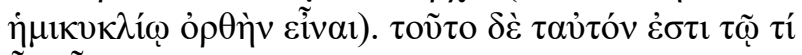

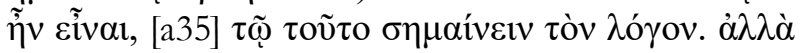

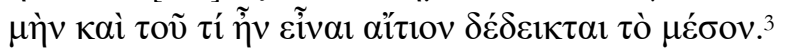

(i) Since we think that we know something when we know its cause, and there are four causes - one, what it is to be something; one, the 'given what things, is it necessary for this to be'; another, what initiated the change; and fourth, the purpose - all of them are proved through the middle term. (ii) For what is such that, given that it is, it is necessary for this to be, occurs not when a single proposition is assumed, but only when at least two are. This is so when the propositions have a single middle term. Thus, when this one item is assumed to be, it is necessary for the conclusion to be. The following example will make things plain. (iii) Why is the angle in the semicircle a right angle? Given what thing, is it right? Let us

${ }^{3}$ Reading $\tau$ oṽ a35 with most manuscripts ( $\tau$ ò Ross) and omitting ǒv a36, added by Ross. See Barnes (1994), 59. 
assign letter 'A' to right, 'B' to half of two rights, ' $\mathrm{C}$ ' to the angle in the semicircle. $\mathrm{B}$ explains why $\mathrm{A}$, right, belongs to $\mathrm{C}$, the angle in the semicircle. For $\mathrm{B}$ is equal to $\mathrm{A}$, and $\mathrm{C}$ to $\mathrm{B}$ (it is half of two rights). Thus, given that $\mathrm{B}$, half of two rights, is, A holds of $\mathrm{C}$ (which was that the angle in the semicircle is a right angle). And this is the same as what it is to be it, insofar as this is what its account signifies. But it has also been shown that the middle term is cause of the what it is to be.

In (i), three of the four kinds of cause are introduced by the standard phraseology that we encounter in several Aristotelian works, while for the remaining case, which occupies the slot belonging by default to material cause, Aristotle offers the phrase 'given what things, is it necessary for this to be'. This description of material cause is not paralleled anywhere, and, surprisingly, is very reminiscent of the definition of the syllogism 4 . In (ii) Aristotle offers a clarification regarding the material cause: a single middle term requires two syllogistic premises. This implicitly rests on the point, familiar from the Prior Analytics, that from one premiss nothing follows of necessity. ${ }^{5}$ On a first reading it might appear a comment on all kinds of causes, but in fact it is clarified by the example illustrating material causation (section iii).

The most immediate problem raised by this characterization of the material cause in (i) and its clarification in (ii) is that the other three causes too are

\footnotetext{
${ }_{4}$ Prior Analytics I 1, 24b18-20, cited below. For descriptions of the syllogism still closer to the phrase under examination see Prior Analytics 1 10, 30b31-33; II 53b11-15; 4, 57a36-b17; Posterior Analytics I 10, 76b38-39; II 5, 91b14-17.

5 Prior Analytics I 15, 34a16-21; 23, 40b35-36 ; cf. Posterior Analytics I 3, 73a7-11.
} 
described as a single middle term occurring in the two premisses of a syllogism. On such a general description of the material cause, therefore, every instance of any of the four causes would also be a case of material causation. Could then material causation be conceived of as a general form of causality underlying the other kinds of cause in virtue of the simple fact that all ascriptions of causes, i.e. all scientific explanations, are accommodated within a syllogism?6

In order to answer this question, it is crucial to address first the question as to what kind of causality, if any, can be associated with syllogistic necessity. Consider the definition of the syllogism:

A syllogism is an argument in which, certain things being posited, something different from the things posited results by necessity, in

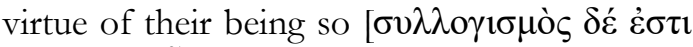

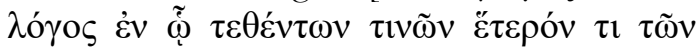

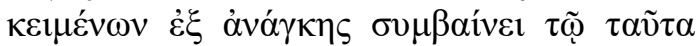
Eivval]. (Prior Analytics I 1, 24b18-20)

If anything alludes to a causal role in this definition, this is the clause 'in virtue of their being so'. This clause of the definition of a syllogism, however, is conspicuously absent from the formulation in our chapter, which only articulates necessitation more in general. Indeed, the wording $\tau$ cò $\tau$ ív $\omega v$

${ }^{6}$ For an unquestioningly affirmative answer to this question, see the anonymous commentary on the second book of the Posterior Analytics edited by M. Wallies in the Commentaria in Aristotelem Graeca, vol. XIII, p. 568.18-31, Eustratius, In Analyticorum Posteriorum Librum Secundum Commentarium, 137.22-26 Hayduck, and, among modern commentators, Mignucci (1972) and Delcomminette (2018), 166-167. Similar interpretation in Ferejohn (2013), 106. 


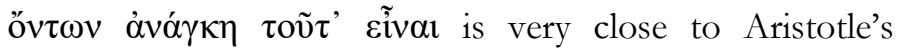
description of the 'necessary consequence', $\tau$ ò $\alpha v \alpha \gamma \kappa \alpha$ ĩov, which, as he says, covers a broader compass than the syllogism:

In some arguments it is easy to see what is missing, but others escape our notice and appear to be proper syllogisms, because something necessary results from the assumptions. [...] We are deceived in these cases because something necessary results

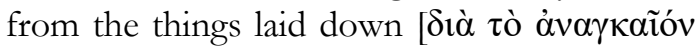

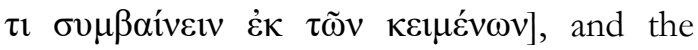
syllogism too is something necessary. But necessity extends beyond the syllogism, for while every syllogism is necessary not every thing that is necessary is a syllogism. (Prior Analytics I 32, 47a22-35)

According to an influential interpretation of this passage, the difference between generic necessary consequence and the syllogism is precisely the clause in virtue of their being so', which only appears in the definition of the latter. ${ }^{7}$ This difference suggests that the material cause described at 94b21-22 in our chapter matches only the broad definition of necessary consequence. It is unlikely then that it is introduced to codify the causality typical of syllogistic consequence.

7 Barnes (1981), 22-23; Frede 'Stoic vs. Aristotelian Syllogistic' (1978), repr. in Frede (1987), 99-124, at 110-112. The extension of the necessary is difficult to assess. It does not capture the concept of 'necessary truth preservation' (if the assumption are true, necessarily the conclusion is true); rather it coincides with the class of arguments that can be reduced to syllogisms by 'sensible' additions and suppressions of premisses. See Striker (2007), 215. 
But this is not the most important difference between material and syllogistic necessity. For the crucial difference can be rather described borrowing the medieval distinction between a causa consequendi and a causa essendi. ${ }^{8}$ Even if we were to take the clause 'in virtue of their being so' as implicitly present in the formulation of Posterior Analytics II 11 (in fact, it may seem to be present in a similar description in De Partibus Animalium 677a17-19, to be discussed below), this clause does not imply that the premisses in virtue of which the conclusion follows are true, but only that, if they are assumed, then the conclusion follows. Thus, what comes about of necessity in virtue of the premisses being so is just the following of the conclusion (causa consequendi). This, of course, is different from the claim that the facts designated by the premisses are the cause of the fact designated by the conclusion (causa essendi). ${ }^{9}$ But it would seem that only this latter claim is able to capture what is needed in order to express any of the four kinds of causality distinguished by Aristotle. Elaborating upon the example offered in 94a29 (to be discussed in due course), Malink (2017), 190 n. 83 observes that in the syllogism:

8 E.g. Peter of Spain, Syncategoreumata, V 4, ed. L.M. De Rijk, Leiden-New York-Köln, Brill, 1992.

9 According to Patzig (1968), 197, in Prior Analytics II 2, 53b7-10 Aristotle would clarify that a syllogism does not always articulate the causa essendi of the conclusion: from false premisses there can be a syllogism of the fact, but not of the reason why: ov $\delta$ เó $\tau$

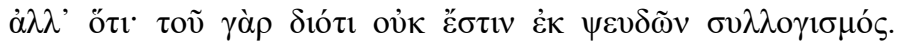
Aristotle promises to justify this claim later on. According to Patzig, the cross-reference is to Posterior Analytics I 2, but Ross indicates instead Prior Analytics. II 4 57a40-b17. If Ross is right, as he may well be, then the $\delta$ ió $\tau \mathrm{l}$ in b7-10 means causa consequendi. 
Every angle in the semicircle is a stone

Every stone is a right angle

Therefore, every angle in the semicircle is a right angle

Though false, the premisses of this syllogism do yield the conclusion in the mere sense of the necessity of the following (and, we may add, the conclusion follows in virtue of the premisses being so'), but they are not an adequate response to the question asked by Aristotle: 'Why is the angle in the semicircle a right angle? Given what thing, is it right?' For that question can only be answered by true and demonstrative premisses. Indeed, in 94a24-27 (section (ii)) Aristotle confirms that material cause too necessitates something as a single middle term, and the middle term is the item 'such that, given that it is, it is necessary for this to be'. This, again, strongly indicates that material causality, whatever it is, cannot be just the causality contributed by syllogistic necessity as such.

We can then answer our first question and confirm that the kind of necessity introduced in (i) at 94a21-22 and explained in (ii) is not just the necessity involved in any syllogism, and in particular in those syllogisms articulating the other three forms of causality. If this is the case, and given that in our chapter necessity plays a precise and limited role in the account of the four causes, there is no reason to doubt that Aristotle is using the concept of necessity strictly to articulate the notion of material cause.

If interpreters could insist that Aristotle envisaged a tighter and special connection between the necessity of the syllogism and the necessity of material causation, this is especially due to a puzzling claim Aristotle makes in the Physics (and in the Metaphysics):

Letters are causes of the syllables in the sense of 'that from which, and the matter of artefacts, fire and the like of bodies, the parts 
of the whole, and the hypotheses of the conclusion. (Phys. II 3, 195a16-19= Metaph. $\Delta$ 2, 1013a17-21)

This passage is cited to confirm that the premisses of any syllogism, here referred to as 'hypotheses', are the matter of the conclusion, and so there is no scandal if in Posterior Analytics II 11 Aristotle introduces matter as a set of syllogistic premisses. ${ }^{10}$ However, Marko Malink (2017)

10 According to Themistius, Analyticorum Posteriorum Paraphrasis, 52.5-11 Wallies, at 94a21-22 Aristotle only offers an example of material causation. As Ross suggests, Themistius must have in mind Physics II 3, 195a16-19, since in that passage the relation of the premisses to the conclusion is in effect only an example of material causation. Themistius' interpretation, also endorsed by Balme 1992, 83, is implausible on two counts, both noted by Ross (1949), 639: (i) Aristotle would have chosen a more familiar example of material causation, and (ii) the other three kinds of cause are not introduced by examples, but by general descriptions. The identification of material necessity with general syllogistic necessity is accepted by Sorabji (1980), $51 \mathrm{n} \mathrm{24}$, and not dispelled by Barnes (1994), 226, who takes our passage to deal with genuine material causation, but still does not exclude that the relation of necessitation at $94 \mathrm{a} 21-22$ is the relation of syllogistic necessitation in general. Mignucci (1998), 69-73 positively accepts the coincidence of the two notions of material and syllogistic necessity, and attempts to explain the concept of logical consequence as a form of material necessitation. Mignucci (1972) had already offered a variant of this interpretation, which has been recently revived by Delcomminette (2018), 166-167 and 134. However, Mignucci (2002), a paper which may be singled out as Mignucci's most comprehensive discussion of syllogistic consequence in Aristotle, does not invoke material necessitation to explain logical necessity. Since Ross's (1949), 640 sui generis interpretation has been very influential, and is the most radical in so far as it ends up extruding matter from the chapter, it deserves a brief summary: since material causes are not really explanatory, Aristotle makes no allusion to the familiar notion of material 
has persuasively argued that the passage only refers to demonstrative syllogisms, not to syllogisms in general. He has also shown that, so interpreted, the analogy between all the items mentioned in the passage - the letters of the alphabet, the material ingredients, the parts, and the hypotheses - is quite pertinent. There is no need for me to rehearse his compelling and exhaustive case here. Allow me then to say that the passage of Physics II 3 is not relevant, and resume the analysis of our chapter.

According to Jonathan Barnes (1994), 227, lines 94a2427 (section (ii)) contain an abstract argument in which Aristotle attempts to show that necessitation is always syllogistic necessitation: Whenever a fact $p$ necessitates a fact $q, p$ can be expressed by a pair of syllogistic premisses, $\mathrm{P}_{1}$ and $\mathrm{P}_{2}$, with a middle term in common, such that they syllogistically entail $\mathrm{Q}$, a proposition expressing $q$. If indeed this is an argument, it is a non sequitur, as Barnes complains; for it is not impossible to conceive of an atomic fact incapable of being divided into two predicative relations expressed by two propositions featuring three terms overall. However, Aristotle may not have intended his

causation here, and the claim in Physics II 3 that the premisses are the matter of the conclusion is not relevant, because it contributes only an example of material causation - and a rather metaphorical one. Instead, Aristotle refers to the relation of 'ground to consequent', which is a purely logical relation, differing from the other forms of causality in not involving the temporal succession of cause and effect. Not all consequences involve a relation between ground and consequent, because this relation is 'eternal and simultaneous', while some consequences connect temporal events, as when an efficient or final cause is involved. According to Ross, this is the reason why Aristotle choses his example of ground-consequent in the field of mathematical truths. The system of the four causes is not, therefore, fully identical to the one familiar from Physics and Metaphysics. 
clarification to be an argument at all. As I understand him, he is rather disarming a potentially misleading formulation peculiar to this kind of cause. Material causation is presented twice as a form of necessity: first in the plural and then in the singular:

- 'given what things, is it necessary for this to be' $\tau$ ív $\omega v$

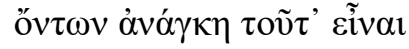

- 'given that it is, it is necessary for this to be' oũ obvios

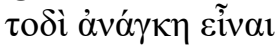

Suppose that material causation is standardly expressed in the singular, e.g. 'if this is, by necessity that is'. This may be understood by the reader as a deduction from one premiss. Aristotle wants to prevent this error, especially since the purpose of the chapter is to show that all of the four causes are couched in syllogistic form, and syllogisms require at least two premisses. It is probably only to avoid this confusion that Aristotle adopts the plural in the first formulation, although this too will be misleading if a reader understands it to the effect that every case of material causation requires the concurrence of at least two causes. Hence Aristotle's explanation in (ii): the singular formulation does not mean that there is only one premiss, but only one causal factor, expressed by the middle term. ${ }^{11}$ The plural formulation does not deny the unicity of the causal factor. It only reflects the fact that, since it is expressed by a middle term connecting a major and a minor term, this causal factor must be bifurcated into two premisses. If material causation is to be described in terms of necessity, either of these formulations, the singular or

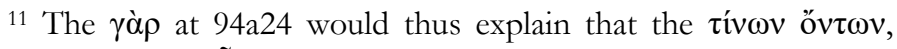

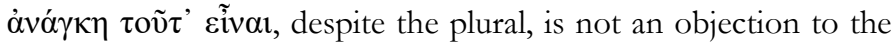

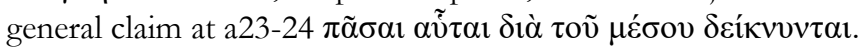


the plural, must be adopted. But both are peculiarly misleading, and either way Aristotle must provide a clarification. ${ }^{12}$ By contrast, a similar gloss is not required for the other three causes, since none of their descriptions misleadingly suggests the sufficiency of one premiss. My surmise, therefore, is that Aristotle is not producing an argument; ${ }^{13}$ rather, he is at pains to clarify a terminological difficulty. If correct, this diagnosis would confirm that the plural formulation is not meant to suggest that material causation is tantamount to syllogistic necessity in its full generality, but only to present material causation in such a way that it can naturally wear its syllogistic form.

To sum up: syllogistic necessity is not identical to material necessity, nor is it a replacement for material necessity in the chapter. If Aristotle describes material necessity in terms that are so close to his description of syllogistic necessity, it is just to show that a single necessitating middle term can be split into a pair of syllogistic premisses jointly necessitating the conclusion.

If the abstract descriptions of material causation are typically formulated as one singular material item producing

\footnotetext{
12 Couldn't then Aristotle simply avoid referring to material cause as a necessitating cause and less misleadingly call it matter? Yes, but even so, a reference to $\alpha \nu \alpha ́ \gamma \kappa \eta$ would have been required, because here Aristotle is only interested in necessitating material factors, and not every material cause is a necessitating cause, since matter is typically only a sine qua non condition of the outcome.

13 There is no attempt at producing an argument here, because Aristotle does not try to express any material item or fact $p$ as a pair of syllogistic premisses $\mathrm{P}_{1}$ and $\mathrm{P}_{2}$. Rather, when expressed in the singular the material cause is already conceived of as a middle term. A few lines above in the same note, Barnes (1994), 226 comes very close to a recognition of this fact: 'the unusual designation [of matter] reflects the fact that citing the matter of $\mathrm{X}$ is not always genuinely explanatory'.
} 
a certain outcome of necessity, the assumption that this item can always be taken as a causal factor to be cast as the middle term of a syllogism is, as we have seen, not unproblematic. Indeed, in certain contexts it seems that Aristotle conceives of this material factor and its necessity in a way that cannot be articulated, or easily accommodated, within a syllogistic structure. Consider this passage:

We must provide the why in all the ways: that from this necessarily that (from this either absolutely or for the most part); and if that is to be so (as the conclusion from the

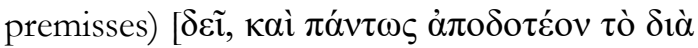

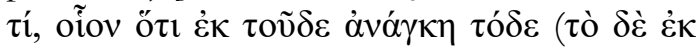

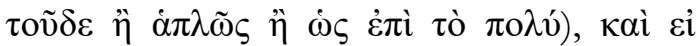

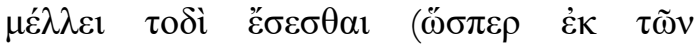

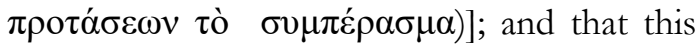
was the what it is to be of the thing; and because it is better in this way (not absolutely, but with reference to the substance of each thing). (Physics II 7, 198b5-9)

The physicist is urged to investigate all forms of causes and probably Aristotle's order of presentation indicates a progression. First she should record the material causation, presumably together with the changes that it brings about: how a lump of matter changes to assume a certain structure. ${ }^{14}$ Second, ${ }^{15}$ she needs to explain the hypothetical

14 Alternatively, the passage could be read as describing a simultaneous explanation involving all the relevant causal factors. This would be the same for my purposes, provided that the regular material changes described as 'from this necessarily that' are recognized a distinctive causal contribution (as for instance the cooling of air in De Partibus Animalium I 1, 642a32-b2 - with 
necessity of the whole material process with a characteristically teleological argument: if such and such a form is to come about, this matter and this process are necessarily present. Third comes a recognition that the end point of the process is the essence of a certain item, and fourth the explanation why the item achieved has thereby acquired the best nature and the best features. The first step of the investigation is just a recognition of certain regular processes yielding the same result always or for the most part. ${ }^{16}$ An example could be the description of the stages of

the comments of Leunissen' 2010b, 109). For a still different interpretation, but less reconcilable with mine, see Angioni

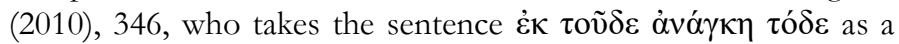
general scheme of causation, and mention Posterior Analytics II 11, 94a21-22 as supporting this schematic reading. Moreover, several interpreters of this passage identify the four steps envisaged by

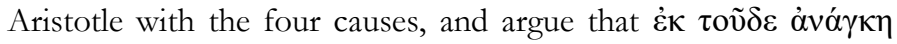
$\tau o ́ \delta \varepsilon$ is the efficient cause (so e.g. Ross 1936, 528; Schofield 1991, 35-37). This is implausible, because $\dot{\alpha} v \alpha ́ \gamma \kappa \eta$ and the preposition $\dot{\varepsilon} \kappa$ point to the material cause. Nevertheless, Aristotle may well take the description to include both matter and its changes leading to a certain outcome (Physics II 9, 200a30-32).

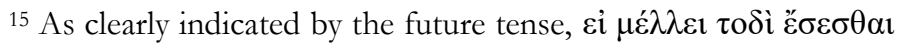
does not refer to material causation, but to the conditional necessitation where matter is just a sine qua non. See Schofield (1991), 37; Angioni (2010), 346, and Malink (2017), 172 n. 25.

16 The proviso that the physicist should identify regular material causations ('always or for the most part') suggests that this is the first step of the physical inquiry, otherwise the regularity would be determined by the regularity of the telos. The suggestion that something may be necessary 'for the most part' is odd (see Schofield 1991, 45). Perhaps we should read: B is necessitated by $\mathrm{A}$, and $\mathrm{B}$ is never (or only rarely) necessitated by another factor C, different from A. Or, alternatively, we may assume that Aristotle is speaking of 'necessity' merely as a special kind of cause, which can in effect hold for the most part (see Kupreeva 
the formation and development of an embryo. However, it is not until the second step of the enquiry is under way that a form of explanatory syllogism (cf. 'as the conclusion from the premisses') with respect to the matter and its processes can be formed. In other words, syllogisms are only possible from the second stage onward, and nothing at the first stage seems to admit or require some sort of ratiocinative explanation. Despite the regularity of material changes, only the teleological order can bring some sense to their process: it is only because there is to be such and such a biological organism that such and such matter must be present and develop in such and such a way.

If this description can be generalized, we begin to understand why in Posterior Analytics II 11 Aristotle feels compelled to modify his description of causal necessitation: the mode 'one item necessitates one item' is normally not read by the physicist as 'one causal factor, to be expressed as one middle term occurring in two premisses, necessitates one item', because the physicist interprets this kind of necessity as a regular, yet still somewhat 'brute' sequence of outcomes. Syllogism plays a role only when the physicist explains such regularities in a teleological framework of hypothetical necessities.

However, in Posterior Analytics II 11 Aristotle is eager to show that each form of cause can be accommodated within the syllogism when this cause alone provides a complete explanation, not when different causal factors interact. ${ }^{17}$ So, if in the processes of matter there is room for genuine material explanations, Aristotle is probably referring only to

2010, 214 and Leunissen 2010b, 99 on the distinction between causal and modal necessity).

17 Pace Pellegrin (1990), 216, who thinks that the formal cause is present in all examples of the chapter: 'ce chapitre 11 [nous propose] un schéma où la cause formelle est mise en facteur commun, c'est-à-dire est présente partout'. 
those cases, and for sure he does not have in mind the teleological argument proving hypothetical necessity, which is characteristic of Physics II 8-9 and De Partibus Animalium I 1 but is crucially absent from the whole Posterior Analytics II 11.18

But what could count then as a genuine and exclusively material explanation? Barnes (1994), 226 provides a general account and an example on Aristotle's behalf:

It seems to be the case that if the matter of $\mathrm{X}$ is genuinely explanatory, then it can always be syllogistically accommodated in this way: if $\mathrm{M}$ is some material predicate and $\mathrm{X}$ is necessarily $\mathrm{M}$ (as it might be, men are necessarily of flesh and bones), and if $\mathrm{M}$ really explains why $\mathrm{X}$ is $\mathrm{Y}$ (e.g. why men are mortal) then there will be a demonstration $\mathrm{X}$ is $\mathrm{M}, \mathrm{M}$ is $\mathrm{Y} \vdash \mathrm{X}$ is $\mathrm{Y}$.

Assuming that flesh and bones inescapably deteriorate even without the influence of external factors, and that no teleological explanation of the benefits of mortality is forthcoming, the example seems apposite. ${ }^{19}$ But does Aristotle consider similar arguments featuring matter as the sole explanans? Prima facie, De Partibus Animalium IV 2, 677a 15-19 may be thought to offer an example:

Sometimes nature makes use even of residues for some benefit, yet one should not on this account search for what something is for in

18 Although it briefly appears in Posterior Analytics II 12, 95b31-37. See Kupreeva (2010), 212.

19 Aristotle explains mortality as the result of the mutual opposition of material components. See his De Longitudine et brevitate vitae. 
every case; on the contrary, when certain such things are, many other things result from

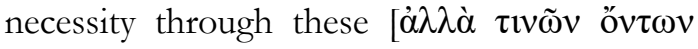

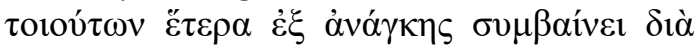
$\tau \alpha \tilde{v} \tau \alpha \pi \mathrm{o} \lambda \lambda \dot{\alpha}]$.

Aristotle is explicit: this kind of necessity is not overseen by a teleological principle; and even if often residuals turn out to be advantageous for an organism, the cases referred to in this passage occur only of necessity. ${ }^{20}$ At first sight Aristotle seems to phrase this material necessity echoing the definition of the syllogism: the premisses are in the plural 'certain such things' and what is 'through these' if not a variant of the clause 'in virtue of these being so' of the official definition of syllogism? ${ }^{21}$ On closer inspection, however, we note that the conclusion is also in the plural, which suggests that Aristotle is taking all the cases of necessitation collectively. If we list them one by one, we cannot rule out a one-to-one correspondence, each antecedent item singly necessitating one consequent. ${ }^{22}$ In this case, 'when certain such things are' would not point to

${ }^{20}$ Leunissen (2010a) and (2010b), 94 discusses these cases as a third residual kind of outcomes coming after 'primary' teleology (matter used for the essential parts of a biological organism) and 'secondary' teleology (residual material outcomes that are exploited by an organism for some good result). For the suggestion that Aristotle has a teleological explanation for these outcomes too see Scharle (2015), 83.

${ }^{21}$ Compare Topics I 1, 100a26-27 (and Sophistici Elenchi 1, 165a2) with Prior Analytics I 1, 24b18-22.

22 Similar case in De Partibus Animalium I 5, 645b32-33. See also IV 12, 694b6, where each putative premiss is described as a cause. For a contrasting view, see Pellegrin (1990), 106, who takes the language of these passages as genuinely pointing to syllogistic structure. 
a plurality of syllogistic premisses jointly entailing one conclusion, but rather to distinct cases of material parts, each producing its own necessary effect.

Later in Posterior Analytics II 11, at 94b27-34, Aristotle also mentions two cases of necessitation which should exemplify a purely material causation: in the first example, light shines through the lantern because the finer body passes through the larger pores of necessity; in the second, thunder is necessitated by the quenching of the fire in the clouds. Probably both cases could be worked out as a purely material causal factor cast as the middle term of a syllogism. These examples are mentioned because they can also be accounted for by a teleological explanation: thunder comes about in order to terrify the dwellers of Tartarus, as the Pythagoreans believed, and the lantern to prevent our stumbling. ${ }^{23}$ But this second causation is additional: the two causes do not cooperate, nor merge in a single multi-causal explanation. So our two cases still qualify as examples of purely material causation. However, from II 11, 94b35-95a9 we can infer that genuinely independent material explanations can only be found in a limited number of cases happening by luck. Aristotle recognizes that there are many things that happen both for a purpose and from necessity, especially in nature. One nature acts for a

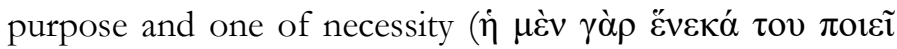

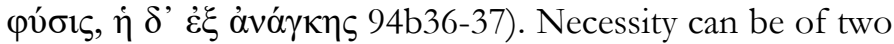
kinds 'according to nature and impulse' and 'by violence and against nature' (94a36-95b3). Certain products of thought (i.e. those involving plans and intentions, like a

${ }^{23}$ The example of the lantern works only if we ignore that it is a product of thought and would never come about spontaneously and by necessity (cf. 95a3-4). The case may perhaps be elaborated: a lit lamp forgotten by someone on a steep flight of stairs prevented me from falling. Still it is not a satisfactory example. 
house or a statue) never come about spontaneously (95a34), because (the reader is invited to infer) they involve necessity against nature. ${ }^{24}$ Other products of thought can be the outcome of natural necessity as well (i.e. the necessity according to nature and impulse), and occur spontaneously. Some of them come about by chance (95a5) - like 'health or safety' when someone discovers a curative herb or finds a natural shelter. But typically, adds Aristotle, when the same outcome can come about either naturally or artificially, it is for a purpose, and therefore not by chance (95a6-9). Despite the oxymoron, it seems that in this chapter natural necessity is for the most part purposeful necessity. ${ }^{25}$

24 Necessity against nature (stones travelling upwards) is presumably mentioned in order to explain the products of thought that never come about spontaneously (95a3-4): If there is to be a house, these stones must be lifted against their natural impulse. According to Leunissen (2010b), 103 'this notion does not seem to play a major role in Aristotle's natural treatises'. I think it must play a role in the production of artefacts (at least in those productive crafts that perfect the outcomes of nature: Physics II 8, 199a15-16). Natural organisms too need to counteract some aspects of their elemental material constituents, but in a more complicated way: see Waterlow (1982), 80-86.

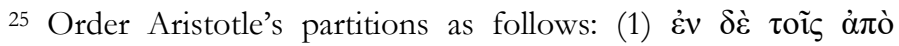

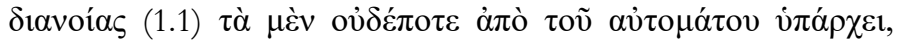

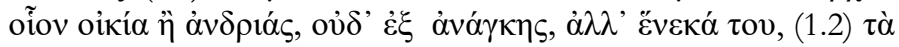

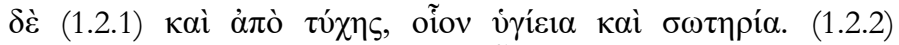

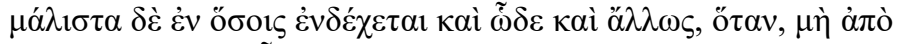

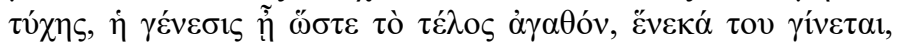

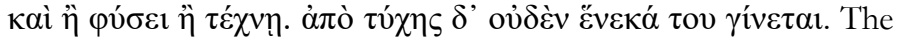
products of thought $(=1)$ are divided into those that come about by purpose and never spontaneously or by natural necessity (= 1.1), and those that may also come about spontaneously by natural necessity $(=1.2)$. Some of the latter happen fortuitously $(=1.2 .1)$, but for the most part $(\mu \alpha \dot{\lambda} \imath \sigma \tau \alpha)$ those outcomes which 
Aristotle is envisaging here the cases discussed in Metaphysics Z 9, in which (e.g.) health itself, being at least partially present in the matter of the organism, produces the very same changes that medicine would produce, and spontaneously heals the organism. But health is present in the matter as form, not as a property of matter itself. Such are the preponderant cases in Posterior Analytics II 11, 94b3495a9, and they are purposeful rather than fortuitous, although necessity according to the natural impulse may sometimes produce good outcomes merely by chance. ${ }^{26}$ If this is the right interpretation, it is reasonable to conclude that cases like the thunder and the lantern are quite marginal, because they belong to the minority of fortuitous good outcomes. Even if they can be cast as syllogisms, they are unlikely to become the focus of scientific inquiry. ${ }^{27} \mathrm{On}$

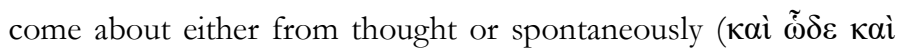
$\alpha \lambda \lambda \lambda \omega \varsigma)(=1.2 .2)$ are not by chance: they are for a purpose even when they occur spontaneously. So, when necessity is natural it can be purposeful. (I thank Christof Rapp and Diana Quarantotto for helpful discussions on this passage.)

${ }^{26}$ Leunissen 2010b, 107 argues that the examples of the thunder and the lantern in II 11 are cases of secondary teleology, where necessity operates independently and yet achieves a good result (although not an essential one). Probably this does not apply to the two examples (which seem to produce good results only by chance), although secondary teleology may be included in the majority of cases where necessity according to nature acts spontaneously, as when the natural presence of health heals an organism. For we have seen these cases too must be accounted for teleologically.

27 It may be objected that necessity according to nature and impulse plays a role also in the cycles of elemental changes described in Posterior Analytics II 12, 95b38-96a7, for that passage somehow suggests that they can be formulated as circular chains of syllogisms. This is problematic in many ways and will not be discussed here. I should also like to acknowledge that, besides the 
the other hand, most outcomes due to natural necessity are not really caused by the matter, and so fail to provide examples of purely material causation.

Metaphysics Z 9 also offers an explicit argument against the idea that cases of natural material causation can be accommodated within a syllogism:

Therefore, substance is the starting-point of all generations, as it happens in the syllogisms. For it is from the what-it-is that syllogisms start; and here [in the arts] the processes of generation <start from the what-it-is $>$. And things which are formed by nature are like these products. For the seed produces them as the artist produces the works of art; for it has the form potentially, and that from which the seed comes has in a sense the same name as

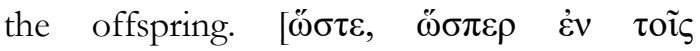

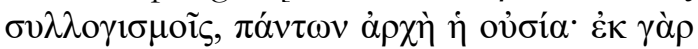

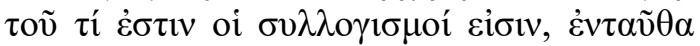

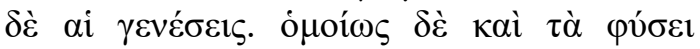

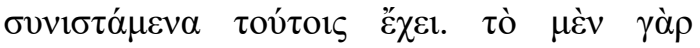

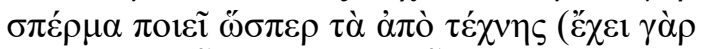

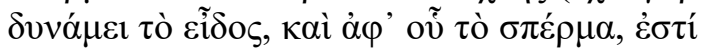
$\pi \omega \varsigma$ ó $\mu \omega ́ v u \mu v$.] (Metaph. Z 9, 1034a30-b1)28

Of course, here 'syllogisms' is a synecdoche for

thunder and the lamp in II 11, occasionally Aristotle offers bona fide examples of material middle terms in the Posterior Analytics: see in particular II 12, 95a16-21 (ice is solidification of water due to complete loss of heat) and II 16, 98b35-38, cf. 17, 99a28-29 (trees shed their leaves due to the solidification of their moisture). Since mine is not a make-or-brake claim, I think it can retain its value even if these objections stand.

${ }^{28}$ Cf. De Partibus Animalium I 1, 640a27-32. 
'scientific demonstrations', and it is clear that their premisses involve definitions or essential predications designating an essence, or a part thereof. This characterization promises to explain material geneseis too and, interestingly enough, can be seen as Aristotle's replacement for Democritus' necessity. This can be gleaned from two parallel passages. In De Partibus Animalium I 1, 642a25-30 Aristotle acknowledges that Democritus had made an inchoate attempt at inquiring into the what-it-is, though he was led by the subject matter itself to do so, and not by any real awareness that this kind of inquiry is crucial in order to investigate nature. On the other hand, Socrates took a serious interest in the what-it-is, but shifted the focus of philosophy from nature to ethics. In Metaphysics M 4 Aristotle sketches the same historical account adding this detail: 'It was fitting that he [Socrates] sought the what-it-is, for he was seeking to syllogize, and the what-it-is is the starting-point of syllogisms' (Metaphysics M 4, 1078b23-27). I find this remark very telling, because such a developmental outline would make little sense if Aristotle thought that material causation, identified with the necessity invoked by Empedocles and Democritus, could be cast in syllogisms like any other cause.

Let us take stock. We have found that:

i) In Physics II 7 the study of material causation appears to occur at a pre-syllogistic stage of inquiry. ${ }^{29}$.

ii) The syllogistic ring of certain descriptions of material necessitation (e.g. $P A$ IV 2, 677a 15-19) is merely superficial.

29 Or, if you prefer the alternative account sketched above in $\mathrm{n}$. 14 , let us say that material causation is merely a non-syllogistic component of an integrated multi-causal explanation. 
iii) The impact of syllogizable purely material explanations in natural science according to Posterior Analytics II 11 must be assessed in light of the concluding comments of the chapter, from which we learn that, for the most part, nature is purposeful. The role for spontaneous events that may be accounted for by a matter-only syllogistic explanation is limited.

iv) Aristotle's historical report on Democritus would make little sense if natural material causes could be formulated as bona fide syllogisms.

All things considered, there is reason to suspect that the peculiar formulation at 94a21-22 may not be suited for biological material explanations, because the necessity of physical matter tends to resists syllogistic formalization. ${ }^{30}$ The reasons for Aristotle's reluctance to apply syllogism is not immediately clear: he may think that material cause always interacts with efficient cause, or that his teleological net is cast even over phenomena which may appear to be purely material. ${ }^{31} \mathrm{Be}$ this as it may, it seems that by putting in the plural, at 94a21-22, a formula which in the singular typically designates the necessity of matter, Aristotle may try to prevent an incautious immediate translation of the jargon of material necessity into the format of syllogistic. And the unexpected choice of a geometrical example to illustrate this kind of cause may be partially due to the difficulty of finding a good and sufficiently representative

30 For discussions of material necessitation dealing with the problem of its explanatoriness (as expressed by a syllogistic middle term) see especially Sorabji (1980), 144-154, and Balme (1992), 82-84.

${ }^{31}$ Ebrey (2015) discusses the first possibility, and Scharle (2015) the second. 
biological example. Conversely, we shall discover in the next section that geometrical proofs provide especially suitable cases of purely material necessitation.

\section{THE GEOMETRICAL EXAMPLE}

The example presented in part (iii) of the passage is clad in syllogistic form through the assignment of letters to the terms ${ }^{32}$ :

R belongs (A) to half of $2 \mathrm{R}$ (B)

Half of $2 \mathrm{R}(\mathrm{B})$ belongs to the angle in the semicircle $(\mathrm{C})$ Therefore, $R(A)$ belongs to the angle in the semicircle $(C)$.

$\mathrm{B}$ is the middle term and a case of material causation (" $\mathrm{B}$ explains why $\mathrm{A}$, right, belongs to $\mathrm{C}$, the angle in the semicircle'). Why should the existence of half of two right angles constitute an example of material causation? To answer this question we need to interrogate a well-known but difficult passage of Physics II 9, where Aristotle notes a surprising analogy between geometrical and biological necessity.

Physics II 9 continues the inquiry started in II 8 how the necessary operates in natural things' and raises the problem whether in nature there is hypothetical necessity or also absolute necessity. The inadequacy of absolute necessity to explain organisms and artefacts is illustrated by a parody of the materialistic and mechanical accounts offered by the physiologoi. A wall would be made of necessity because the stones are heavier, the wood is lighter and they arrange themselves as a wall of their own accord. On the contrary,

32 But not really in proper syllogistic form. No quantification is indicated, and predication and identity are used promiscuously. On this problem see Mendell (1995) and Harari (2004), 92-96. 
those material constituents and their properties are required if there is to be a wall, but they alone cannot bring about a wall spontaneously. The stones and the wood are only hypothetically necessary, a concept illustrated by the famous example of the saw: if a saw is to exist and cut, it must be made of metal. Matter is a sine qua non condition: there would be no saw without metal. Unfortunately, though, Aristotle does not clarify sufficiently the notion of absolute necessity. On the one hand, there is the idea that matter must produce some outcomes by necessity, like in the family of expressions we have been discussing 'from this, that by necessity': fire must heat, rain must fall, etc. On the other hand, there is the rather different idea that matter 'cannot be otherwise': it is metaphysically bound to be there and is an absolute principle governing everything. In the notion of absolute necessity mentioned at Physics II 9, 199b35 Aristotle combines these two ideas (implicitly suggesting that this is the way the physiologists had understood it). He then introduces hypothetical necessity to ensure that the material processes are not absolutely necessary in this full sense, but only necessary if the goal is to come about. So Aristotle does not deny that matter generates necessary outcomes, but argues against the idea that, since (i) matter cannot be otherwise and (ii) it necessarily acts in certain ways and produce certain results, it is the only principle of explanation of all natural outcomes. ${ }^{33}$

33 The crucial passage is De Partibus Animalium I 1, 639b30640a10, to be understood against the background of $D e$ Generatione et Corruptione II 11 (see especially Quarantotto 2005, chapter 4.6, esp. p 196-204 on De Generatione et Corruptione II 11 and p. 208-11 on De Partibus Animalium I 1): biological organisms at the end of a linear transformative process are not absolutely necessitated by their matter because, as individuals, they cannot be connected to the cyclical transformations of matter, which are absolutely necessary and eternal. On hypothetical necessity see 
The passage I wish to focus on, 200a15-30, is part of this discussion:

The necessary is present in mathematics and in the things that come to be according to nature in a somewhat similar way. Since the straight is so and so, it is necessary that the triangle should have angles equal to two right angles, but not: since the latter, the former. But if the latter is not, nor is the straight

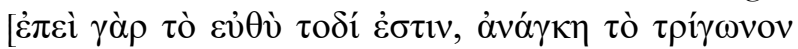

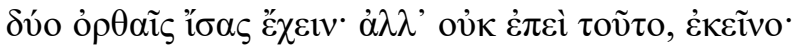

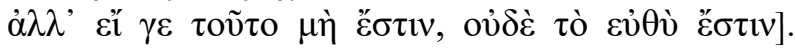
With things coming about for the sake of something

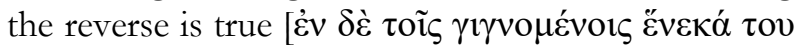
$\alpha \dot{\alpha} \alpha \dot{\pi} \alpha \lambda v v]$ : if the goal will be or is, that also which precedes it will be or is; if not, then, just as there [in mathematics] since the conclusion is not, the starting point will not be, so here the goal and that for the sake of which <will not be>. For this too is a starting point, not of the action but of the reasoning (there [in mathematics], of the reasoning, for there are no actions). So if there is to be a house it is necessary that these come to be or are, and in general the matter relative to the end: bricks and stones if it is a house. But the end is not because of these except as matter, nor will it come to be because of them. Yet if they do not exist at all, neither will the house, or the saw - the former in the absence of stones, the latter in the absence of iron - just as in the other case the principles will not be true if the angles of the triangle are not equal to two right

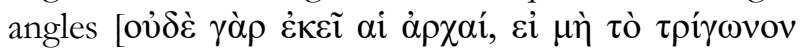

especially Cooper (2004), 130-147 (first published in 1987) and Charles (1988). 


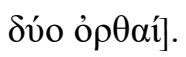

What is the purpose of this elaborate comparison between the two fields of natural physics and mathematics? According to most interpreters (e.g. Ross 1936, 531-532) mathematics is introduced to illustrate inferences which are 'one-sided', i.e. inferences that do not convert: 1 and 2 are true, but $1^{*}$ and $2^{*}$ are false:

1) The straight line is such and such $\rightarrow$ The triangle is $2 \mathrm{R}$

$\left.1^{*}\right)$ The triangle is $2 \mathrm{R} \rightarrow$ The straight line is such and such

2) The end is or will be $\rightarrow$ the means to the end are or will be

$2^{*}$ ) The means to the end are or will be $\rightarrow$ The end is or will be

Aristotle has not chosen a good example: in Posterior Analytics I 12, 78a6-13 he claims that mathematical demonstrations in fact convert more than other kinds of argument. And indeed, on closer inspection, there is a sense in which $1^{*}$ cannot be false: how can the antecedent be true and the consequent false? How can you produce a triangle which is not $2 \mathrm{R}$, if the sides are not straight in the usual sense? Aristotle is aware of this, because he says 'but not: since the latter, the former'. Hence $1^{*}$ should be rather interpreted as denying that the straight is such and such because the triangle is $2 \mathrm{R}$, or so that the triangle might be $2 \mathrm{R}$. 
The mathematical example is a case of mutual implication where only the order of explanation is asymmetrical. ${ }^{34}$

Maybe Aristotle thought that, although imperfect, the comparison with geometry is still helpful, because it shows that biological arguments possess the kind of hypothetical necessity of which geometrical demonstration is a model, with the only proviso that geometrical and physical inferences are the reverse of one another ( $\dot{\alpha} v \alpha \dot{\alpha} \pi \alpha \lambda v)$. This is of the greatest importance in order to understand why material causation operates in geometry and, especially, in the difficult example in Posterior Analytics II 11. Indeed, if Aristotle can describe the order of geometrical objects as the exact reversal of natural hypothetical necessity, it can only be because in the latter the inference goes from the complex (the organism) to the simple (the parts and the elementary material constituents), while in geometry it goes from the simple (the straight) to the complex (the triangle). Further information on this opposition can be obtained by reflecting on a famous remark on geometrical analysis. Notice first that in Nicomachean Ethics VII 8, 1151 a16 Aristotle says that in praxis the for-the-sake-of-which is a starting point in the way in which hypotheses are starting points in geometry. This, I take it, is the same analogy we encountered in Physics II 9.35 Earlier in the Nicomachean Ethics, Aristotle compares the process of deliberation,

34 Helpful discussion in Angioni (2010), 385-392, who cites Categories 12, 14b10-22: mutual implication is compatible with an asymmetrical explanatory order.

35 Since Aristotle quite frequently deploys the craft analogy to illustrate biological generation - and in particular in our passage of Physics II 9 - I feel entitled to take this remark on the logical structure of praxis as equivalent to the comparison developed in that chapter of the Pbysics. 
required to discover the means to the practical goal, and geometrical analysis: ${ }^{36}$

For the person who deliberates seems to inquire and analyze in the way described as though he were analyzing a geometrical construction (it seems that not all inquiry is deliberation - mathematics for example- but all deliberation is inquiry), and what is last in the order of analysis seems to be first in the order of becoming. (III 3, 1112b19-24).

We may complete Aristotle's thought as follows: if in praxis the discovery of the means to the end - or, we may add, in biology the discovery of the material components of an organisms - is like the process of geometrical analysis whereby a complex construction is reduced to its elementary components, and if, furthermore, it is the opposite of geometrical proof from hypotheses, the latter will be best understood as a synthesis where a complex construction comes into being starting from basic constructions. In this sense, the objects of geometry enjoy the kind of progressive or forward-looking necessity typical of the material processes as they are described by the physiologoi: matter brings about certain increasingly complicated outcomes and configurations by necessity. Likewise, in geometry increasingly complex constructions are necessitated by the simpler ones.

Moreover, Aristotle describes geometrical constructions as actualizations of certain potentialities (see Metaphysics $\Theta$ 9, 1051a21-33, quoted below, n. 40), and presumably geometrical constructions actualize potentialities inherent in

36 On geometrical analysis see also Posterior Analytics I 12, 78a6-13; Sophistici Elenchi 16, 175a27-30, and Menn (2002). 
intelligible matter. ${ }^{37}$ The latter can be identified as extension: lines, planes, and solids are actualizations in one dimensional, two dimensional and three dimensional extendedness. If extension or intelligible matter is to some extent like physical matter, it possesses some properties and puts some constraints on the potential constructions. These constraints are expressed by certain elementary definitions, like 'the straight is such and such' which we found in Physics II 9. If these constraints derive from intelligible matter, it is reasonable to say that matter provides the ultimate foundation of geometrical constructions. ${ }^{38}$ At each stage of

37 Intelligible matter is mentioned rarely and poorly described: Metaphysics Z 10, 1036a9-12 (cf. 1035a12); 11, 1037a2-5; H 6, 1045a33-36. Consider one individual geometrical circle C: until you draw the diameter, in $\mathrm{C}$ there are two semicircles, but only in potentiality. Intelligible matter is the substratum that can be affected by a similar division. See Mueller (1970). Barnes (1994), 227 invokes intelligible matter to explain Aristotle's example in our passage.

38 This would not be the case if one conceived of intelligible matter as even more 'malleable', and thus capable of receiving different forms, as for instance two different kinds of straightness, eventually shaping two different geometries (one in which triangles are $2 \mathrm{R}$ and one in which they are not). It is a fact that Aristotle can conceive of a systematic and consistent alteration of the first hypotheses of geometry (e.g. Eudemian Ethics II 6, 1222b24-42), but this alteration may be described in two ways: as a reshaping of one and the same intelligible matter, or as a totally different definition of intelligible matter. Unfortunately, no passage that I know of rules out the first possibility, but Aristotle's commitment to the entirely synthetic nature of geometry in Physics II 9 makes me incline to the second. Indeed, unless the straight is not determined by intelligible matter, we are bound to admit that the straight bypothetically necessitates intelligible matter, which would undermine Aristotle's comparison in Physics II 9. 
the demonstration the permissible constructions are those licensed by the previous constructions and the constraints of matter.

Let us now apply these results to the geometrical example in Posterior Analytics II 11. There are two options: ${ }^{39}$

1. Aristotle takes for granted the constructive part of a proof he describes at Metaphysics $\Theta$ 9, 1051a21-33 and our passage only lays down its deductive backbone. ${ }^{40}$ The triangle $\mathrm{ABC}$ (see figure below) is isosceles and a

${ }^{39}$ Euclid, Elements, III 31 has also been suggested as a possibility (Novak 1978), but it is a significantly different proof of the same proposition and involves a construction never mentioned by Aristotle.

40 Metaphysics $\Theta$ 9, 1051a21-33: 'Geometrical diagrams/ demonstrations [ $\delta 1 \alpha \gamma \rho \alpha \dot{\alpha} \mu \alpha \tau \alpha]$ are also discovered by means of the actuality, for they discover by dividing. If they had been divided, they would have been evident. But as it is they are present in in potentiality. (a) Why is the triangle two right angles? Because the angles around one point are equal to two right angles. So, if the line parallel to the side had been drawn up, it would have been clear immediately on seeing it. (b) Why is there universally a right angle in the semicircle? Because if three lines are equal, the two which are the base and the one which is erected straight from the centre, it is clear on seeing it to one who knows that [i.e. the first proposition]. So, it is evident that the things which are in potentiality are discovered by being brought into actuality. The reason is that the actuality is thinking. So the potentiality is from actuality, and this is why they know by doing ( $<$ and this is not a problem, $>$ for the individual actuality is posterior in generation.' Aristotle hints to two propositions (a) the sum of the internal angles of a triangle is $2 \mathrm{R}$, and (b) the angle in the semicircle is R. The proof of (b) uses (a). The version of the proof of Metaphysics $\Theta 9$ is incomplete, since Aristotle thinks he has shown that there is 'universally a right angle'. On this problem see Mendell (1994) and Hasper (2011). 
perpendicular to the diameter $\mathrm{AB}$ is erected from centre $\mathrm{O}$. $\mathrm{AO}, \mathrm{OB}$ and $\mathrm{OC}$ are all radii and form the isosceles triangles $A B O$ and $O B C$. It is easy to see that, since $\beta=R$, $\alpha+\alpha+\alpha+\alpha=2 \mathrm{R}$, the angle $\mathrm{ABC}=\alpha+\alpha=1 / 22 \mathrm{R}$. As it is, however, the proof does not apply to an arbitrary angle in the semicircle but only to a special case. It can be generalized by applying a proposition proved in Euclid (III 21): any two angles in the same segment of a circle are equal. ${ }^{41}$

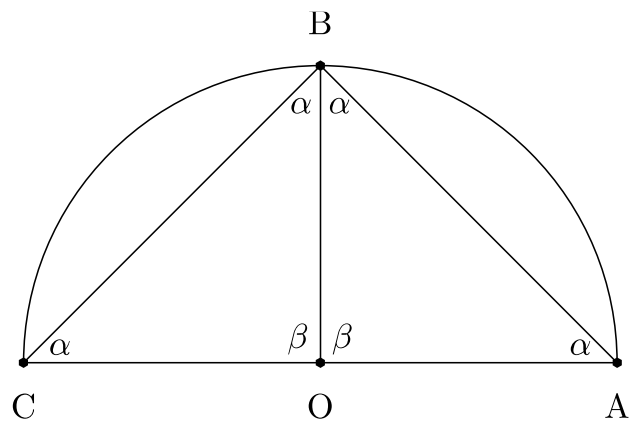

2. Aristotle's syllogism presupposes a construction differing from the version of the Metaphysics. This proof was known in antiquity because it is reported by several manuscripts of the Elements as an alternative of III 31. Although it relies on Euclid's construction for the official III 31, it can be presented as in the figure below: unlike in Aristotle's version, there is no erection of the perpendicular from the centre. Instead, given an arbitrary angle $A B C$ in the semicircle, we draw from the vertex to the center a radius $\mathrm{OB}$. $\mathrm{AO}, \mathrm{OB}, \mathrm{OC}$ are all radii, so the triangles $\mathrm{ABO}$ and $\mathrm{OBC}$ are isosceles. Since the external angle of a triangle is equal to the two opposite internal angles (Euclid I 32), $\gamma$

41 Ross (1949), 641 adopts this version of the proof. See Makin (2006), 235-237 for discussion. 
$=2 \alpha$ and $\beta=2 \delta$. Therefore $\beta+\gamma=2(\alpha+\delta)$, but since $\beta+\gamma$ $=2 \mathrm{R}, \alpha+\delta=\mathrm{R}$. So the angle in the semicircle $(=\mathrm{ABC}=$ $\alpha+\delta)=\mathrm{R} .{ }^{42}$

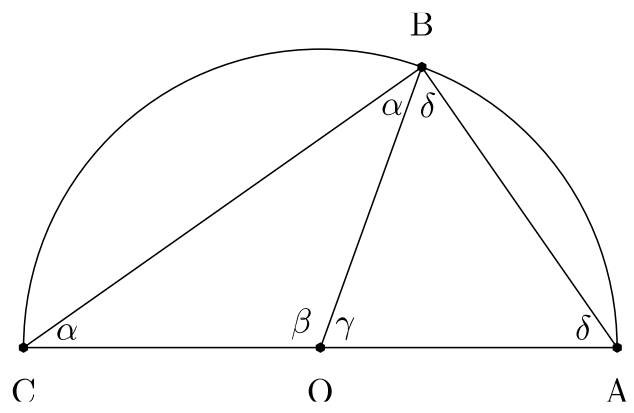

Despite its shortcomings, I think that we are better off adopting the incomplete version of the proof attested in the Metaphysics (first proof above), and assuming that the same construction is also presupposed in the example of the Posterior Analytics. That proof offers interpretative advantages that make up for its lack of generality. They are best appreciated when seen in contrast to the defects of the second proof. In the latter it seems that the middle term 'being half of two right angles' plays no significant explanatory role. It is rather a necessary consequence of a construction. The most fundamental determination on which the proof rests is in fact the assumption that $\beta+\gamma=$ $2 \mathrm{R}$. And that a flat angle is $2 \mathrm{R}$ is also indicated in Metaphysics $\Theta 9$ as the reason why the sum of the angles of a triangle is $2 \mathrm{R}$ ("Why is the triangle two right angles? Because

42 See Heiberg's edition of the Elements, vol. I, 332.10-17 (and Heath (1908), vol. II, p. 64 for the translation). This version of the proof is considered by Heath (1949), 72, and adopted by Leunissen (2010b), 185 in a slightly different form: $2(\alpha+\delta)+\beta+\gamma$ $=4 \mathrm{R}$, but since $\beta+\gamma=2 \mathrm{R}$, we have that $2(\alpha+\delta)=2 \mathrm{R}$. Therefore $\alpha+\delta=\mathrm{R}$. 
the angles around one point are equal to two right angles', see n. 40). It would be reasonable then that this should be recast as an explanatory middle term in our passage too, if the second proof, where this assumption plays the most fundamental explanatory role, is indeed what Aristotle has in mind.

If, on the other hand, Aristotle's syllogism presupposes the erection of the perpendicular, as in our first construction, it is true that when the perpendicular halves the plane angle at the centre of the diameter, it generates 'half of two right angles' in a way that is truly explanatory and offers a reason for Aristotle's indication of the middle term. For in the first proof 'being half of two right angles' plays a role analogous to definition I 10 in Euclid: 'when a straight line set up on a straight line makes the adjacent angles equal to one another, each of the equal angles is a right angle'. ${ }^{43}$ But what in Euclid is given as a basic definition, here is incorporated in a construction. Nevertheless, it could also be a construction defining the right angle - which would explain why, having illustrated the material causation by means of this proof, Aristotle says 'and this is the same as what it is to be it, insofar as this is

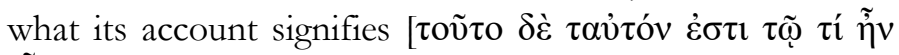

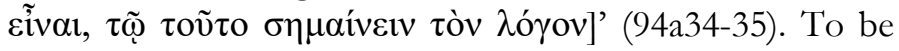
sure, he does not specify whether the middle term articulates the 'what it is to be' of the major or the minor term. But being half of two right angles (in the constructive sense specified), can only be the essence of the right angle,

${ }^{43}$ Novak (1978) correctly notes that the description 'half of two right angles' is reminiscent of Euclid, def. I 10, but wrongly infers that the proof presupposed must then be Euclid III 31, because it uses that definition. As I said, however, III 31 involves a construction that does not match Aristotle's description of that proof. 
i.e. the major term, not of the angle in the semicircle. ${ }^{44}$ This is then another good reason for preferring the first construction over the second: there is a sense in which being half of two right angles is the 'what it is to be' of the right angle.

Why is being half of two right angles a material cause? Notice that in the discussion of the same theorem in Metaphysics $\Theta 9$, cited above, n. 40, Aristotle presents geometrical constructions as divisions already present in potentiality in the geometrical diagrams ('Geometrical diagrams are also discovered by actuality, for they [geometers] discover by dividing. If they had been divided, they would have been evident. But as it is, they are contained in potentiality'). ${ }^{45}$ Although Aristotle speaks of divisions, we can generalize his claim to every sort of

44 Pace Barnes (1994), 227. See Pellegrin (1990), 106. For this model of demonstration in which the middle term is (part) of the essence of the major see Bronstein (2016), 48 and passim.

45 The mathematical passage of $\Theta 9$ is probably a coda to the discussion of the priority of actuality over potentiality in $\Theta 8$ (especially 1049b29-50a3: you acquire the disposition to play the flute by actually playing it). Aristotle shows that, unlike what Plato suggests in the Meno, mathematical discovery is no exception: it is not the actualization of a pre-existent potentiality dormant in the soul. First comes the noetic grasp, which is present in the mind in full actuality as soon as an illuminating construction present in potentiality within the diagram (NB not in the mind) has been actualized. This initial actuality, in turn, originates the potentiality in the mind, i.e. the disposition to repeat the proof. When Aristotle says that 'the things which are in potentiality are discovered by being brought into actuality', it is difficult to unravel what exactly gets actualized: the construction, the geometrical property discovered or both? On mathematical constructivism in Aristotle's time see Proclus, In Primum Euclidis Elementorum Librum Commentarii. 77-78; Niebel (1959); Bowen (1983). 
construction. ${ }^{46}$ Constructions thus include the drawing of the parallel to the side of a triangle and the erection of a perpendicular of the diameter from the centre to the circumference. Of course, the geometer can actualize certain potentialities rather than others. And the actualization yields knowledge of a truth whenever it makes certain properties of the diagram apparent ('Geometrical diagrams/demonstrations are also discovered by means of the actuality... So it is evident that the things which are in potentiality are discovered by being brought into actuality', see n. 40). The action of erecting a perpendicular is therefore the actualization of intelligible matter. On the other hand, we have seen that, according to Aristotle, a complex construction is the result of the suitable complication of simpler constructions. At each stage of the proof, therefore, the geometer can actualize certain potentialities limited only by the previous constructive steps of the proof and by the general constraints imposed by intelligible matter. As I understand the difficult line where Aristotle says that the same geometrical proof also gives the 'what it is to be' (94a34-35), the proof exhibiting material causation shows at the same time a formal explanation, because in geometry (unlike in biology) the geometrical entities and their properties have no real definition that may be given independently of, and prior to, what is necessitated by increasingly complex actualizations of intelligible matter (in contrast to the products of crafts like the axe or the saw, and the organisms of teleologically oriented nature). The half of two right angles, like the triangle with the sum equal to two right angles of Physics II 9, has no formal nature existing ahead of its construction, a nature which may be used by the geometer to shape malleable geometrical

46 And we can ignore here the distinction between problems (constructions of a set geometrical figure) and theorems (construction-involving demonstratiuon of a geometrical truth). 
matter. ${ }^{47}$ The 'what it is to be' plays a secondary role and can only be an expression signifying the constructions actualized by the geometer. This is why, I think, Aristotle

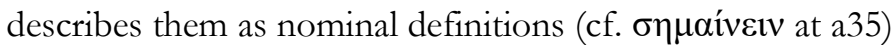
and is unfazed by the otherwise puzzling circumstance that a material cause is also a formal cause. 48

\section{CONCLUSION}

What have I achieved in this paper? First, by explaining Aristotle's motivation for switching to the plural in his description of material necessity at 94a21-22, I have contributed to dispelling the persistent confusion of material and syllogistic necessity that has haunted interpretations of the passage. Second, I have raised the suspicion that Aristotle deliberately avoids biological examples when he tries to accommodate purely material causation syllogistically. Third, by working out some indications Aristotle provides on the nature of geometrical proof, I have proposed an explanation as to why geometrical demonstrations can be said to be entirely based on material necessitation.

47 Which does not exclude that the geometer must figure in advance what she wants to achieve as the final result, so to arrange all the steps of the construction in the right order.

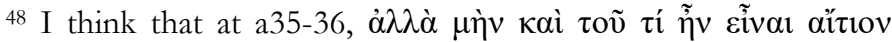

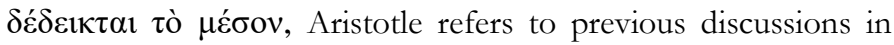
the treatise where, he believes, examples of the formal cause have been provided. 


\section{REFERENCES}

Angioni, L. Aristóteles Física I-II, Campinas, Editora da Unicamp, 2010.

Balme, D.M. Aristotle, De Partibus Animalium I, De Generatione Animalium I, Oxford, Clarendon, 1992.

BARneS, J. 'Proof and the Syllogism', in E. Berti (ed.), Aristotle on Science: The Posterior Analytics, Padova, Antenore, 17-59, 1981.

_ Aristotle's Posterior Analytics, 2nd ed., Oxford, Clarendon, 1994.

BOwEn, A.C. 'Menaechmus versus the Platonists: Two Theories of Science in the Early Academy', Ancient Philosophy, 3, 12-29, 1983.

Bronstein, D. Aristotle on Knowledge and Learning, Oxford, Oxford University Press, 2016.

Charles, D. 'Aristotle on Hypothetical Necessity and Irreducibility', Pacific Philosophical Quarterly, 69, 1-53, 1988.

CoOper, J. Knowledge, Nature and the Good. Essays in Ancient Philosophy, Princeton and Oxford, Princeton University Press, 2004.

Delcomminette, S. Aristote et la nécessité, Paris, Vrin, 2018.

Detel, W. Analytica Posteriora, Berlin, Academie Verlag. 1993.

Ebrey, D. 'Blood, Matter, and Necessity', in Id. (ed.), Theory and Practice in Aristotle's Natural Science, Cambridge, Cambridge University Press, 61-76, 2015. 
FEREJOHN, M. Formal Causes, Oxford, Oxford University Press, 2013.

Frede, M. Essays in Ancient Philosophy, University of Minnesota Press, Minneapolis, 1987.

Harari, O. Knowledge and Demonstration. Aristotle's Posterior Analytics, Dordrecht-Boston-London, Kluwer, 2004.

HASPER, P.S. 'Being Clear about the Explanation: A Mathematical Example in Aristotle, Metaphysica $\Theta$ 9. 1051a26-29', Classical Quarterly, 61, 172-177, 2011.

Heath, TH. Euclid, The Thirteen books of the Elements, 3 vols, Cambridge, Cambridge University Press (2nd edition: New York, Dover, 1956), 1908. Mathematics in Aristotle, Oxford, Clarendon, 1949.

Kupreeva, I. 'Aristotle on Causation and Conditional Necessity: Analytica Posteriora II 12 in Context', in F. de Haas, M. Leunissen, M. Martijn (eds.), Interpreting the Posterior Analytics in Late Antiquity and Beyond, Leiden-Boston, Brill, 203-234, 2010.

LEUNISSEN, M. Nature as a Good Housekeeper. Secondary Teleology and Material Necessity in Aristotle's Biology', Apeiron, 43, 117-142, 2010a.

Explanation and Teleology in Aristotle's Science of Nature, Cambridge, Cambridge University Press, 2010b.

MAKIN, S. Aristotle, Metaphysics Book Theta, Oxford, Clarendon, 2006.

MALINK, M. 'Aristotle on Principles as Elements', Oxford Studies in Ancient Philosophy, 53, 163-213, 2017.

Mendell, H. 'Two Geometrical Examples from Aristotle's Metaphysics', Classical Quarterly, 34, 359-372, 1994. 
'Making Sense of an Aristotelian Demonstration', Oxford Studies in Ancient Philosophy, 16, 161-225, 1998.

Menn, S. 'Plato and the Method of Analysis', Phronesis, 47, 193-223, 2002.

MignUCCI, M. 'Di un passo controverso degli Analitici Secondi di Aristotele', in Scritti in onore di C. Giacon, Padova, Antenore, 63-86, 1972.

'What is an Aristotelian Syllogism?', in N. Avgelis, F. Peonidis (eds.), Aristotle on Logic, Language and Science, Thessaloniki, Sakkulas Publications, 57-73, 1998.

'Syllogism and Deduction in Aristotle's Logic', in M. Canto-Sperber, P. Pellegrin, Le style de la Pensée. Recueil de textes en hommage à Jacques Brunschwig, Paris, Les Belles Lettres (reprinted in M. Mignucci, Ancient Logic, Language, and Metaphysics, ed. by A. Falcon and P. Giaretta, London, Routledge, 2019: 3-19), 2002.

NIEBEL, E. Untersuchungen über die Bedeutung der geometrischen Konstruktion in der Antike, Köln, Kölner UniversitätsVerlag, 1959.

NovaK, J.A. 'A Geometrical Syllogism, Posterior Analytics II 11', Apeiron, 12, 26-33, 1978.

Patzig, G. Aristotle's Theory of the Syllogism, Dordrecht, Reidel, 1968.

Pellegrin, P. 'De l'explication causale dans la biologie d'Aristote', Revue de Métaphysique et de Morale, 95, 197219, 1990.

QuARAntotTo, D. Causa finale, sostanza, essenza in Aristotele., Napoli, Bibliopolis, 2005.

Ross, W.D. Aristotle's Physics, Oxford, Clarendon, 1936. 
Aristotle's Prior and Posterior Analytics, Oxford, Clarendon, 1949.

SCHARLE, M. "And These Things Follow": Teleology, Necessity, and Explanation in Aristotle's Meteorologica, in D. Ebrey (ed.), Theory and Practice in Aristotle's Natural Science, Cambridge, Cambridge University Press, 79-99, 2015.

SCHOFIELD, M. 'Explanatory Projects in Physics, 2.3 and 7', Oxford Studies in Ancient Philosophy, Supplementary Volume, 29-4, 1991.

SORABJI, R. Necessity, Cause and Blame, Cornell, Cornell University Press, 1980.

STRIKER, G. Aristotle, Prior Analytics Book I, Oxford, Clarendon, 2007.

WAterlow [BroAdiE], S. Nature, Change, and Agency in Aristotle's Physics, Oxford, Oxford University Press, 1982.

$(\mathrm{cc}) \mathrm{BY}$ 